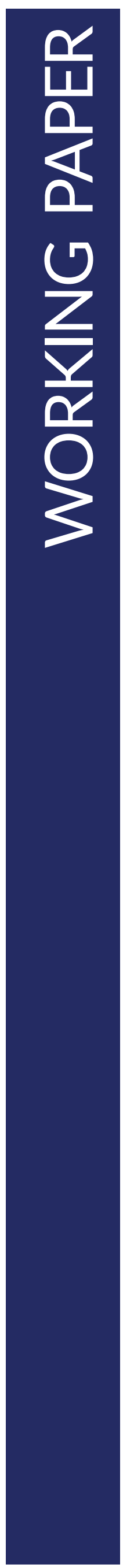

\title{
Impact Lessons: Engaging Research with Global Movements
}

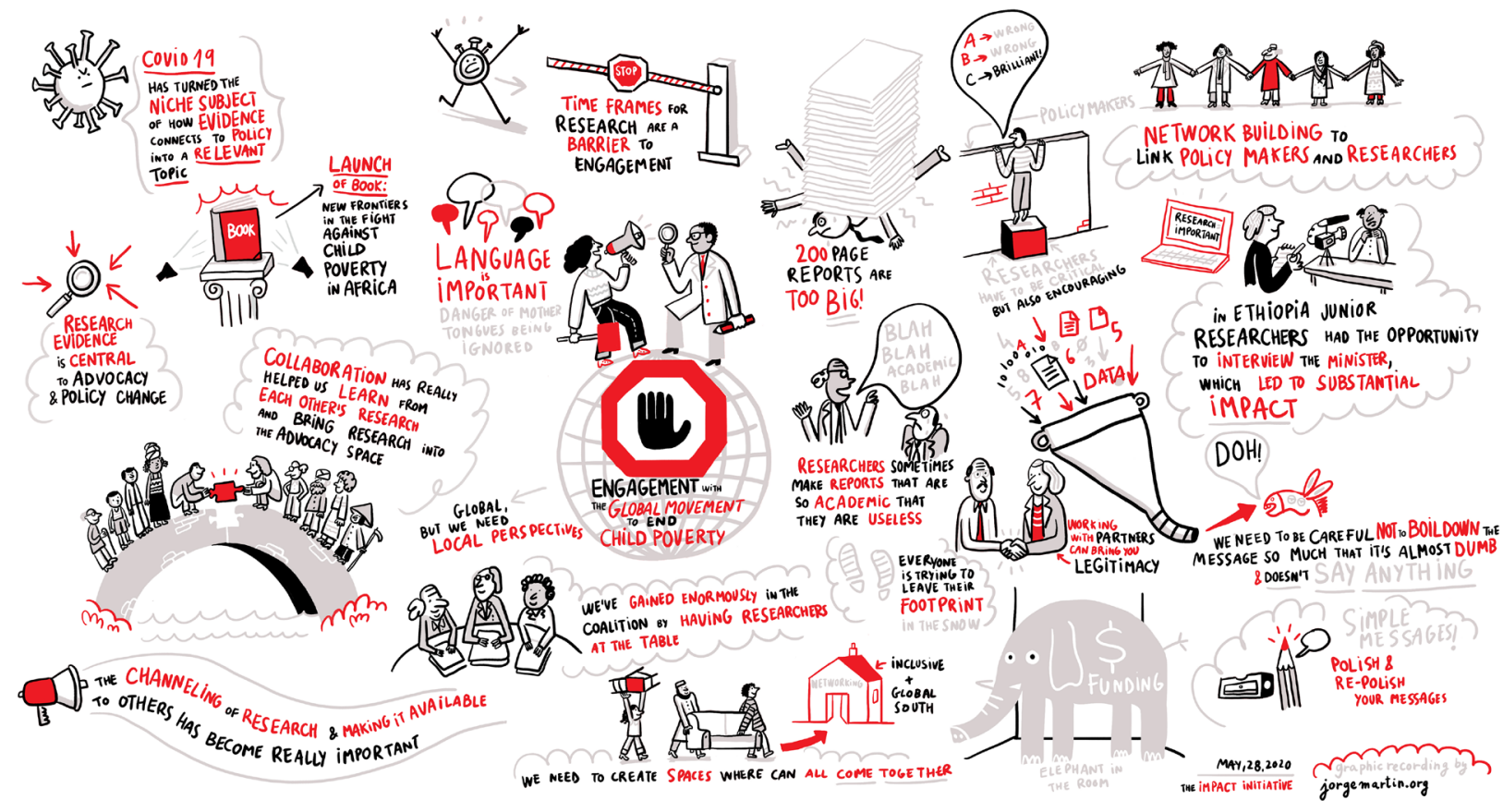

Figure 1: Visualisation of the online discussion focusing on engaging with global movements. Image: (CJorge Martin 2020

\section{THE IMPACT INITIATIVE PROGRAMME}

The Impact Initiative programme, funded by the UK's Economic and Social Research Council (ESRC) and Department for International Development (DFID), aims to increase the uptake and impact of two major ESRC-DFID international development research portfolios. As part of these portfolios' commitment to share learning and develop a better understanding of how good knowledge brokerage for development happens, in $\mathbf{2 0 2 0}$ the Impact Initiative is leading a series of online discussions.

\section{BACKGROUND}

Each virtual event is planned to highlight standout examples of particular impact pathways and strategies that have emerged over the course of the Impact Initiative programme. The online discussions aim to produce practical learning for those seeking to maximise the impact of research, particularly where they work across broad portfolios or large programmes.

The first of these online events focused on the engagement between researchers and global advocacy movements, and how research evidence can be placed front and centre when advocating for change. It concentrated on one pathway: engagement with global advocacy movements.
The Global Coalition to End Child Poverty is a global initiative to raise awareness about children living in poverty across the world and support global and national action to alleviate it. More than 20 organisations work together as part of the Coalition to achieve a world where all children grow up free from poverty, deprivation, and exclusion. Source: The Global Coalition to End Child Poverty (2020)

The event provided an opportunity to further learn about the opportunities and challenges of engaging research from the North and the global South with an international movement that combines policy actors and civil society organisations. 
On 28 May 2020, 35 international campaigners, researchers, policy actors, and donors attended the virtual event to explore the opportunities and challenges of engaging research with international movements focused on improving the lives of children. The discussion reflected on the Impact Initiative's work with the Global Coalition to End Child Poverty, which has involved a diverse group of ESRC-DFID grant holders.

This specific pathway to impact was chosen as the Impact Initiative programme team holds a strong belief that research impact can be enhanced by engaging with advocacy partners who are experts in the local political realities. Previous work in this area had identified how partners are able to provide a necessary understanding of the context, improving the likelihood that research is accepted.

The discussion built upon an analysis of the portfolio funded by ESRC-DFID that showed a critical mass of relevant research relating to the objectives of the Coalition. Having identified the relevant research grants, the Impact Initiative matched the supply with the demand for evidence and helped to coordinate a range of successful activities that aimed to build support from the Coalition leadership for more focus on research. This then led to a collaboration to deliver a dynamic conference in October 2017 in Addis Ababa - 'Putting Children First: Identifying Solutions and Taking Action to Tackle Poverty and Inequality in Africa'. Around 200 delegates attended the conference, which was co-organised by Coalition members including UNICEF and Save the Children as well as the United Nations Economic Commission for Africa (UNECA), Africa Child Policy Forum (ACPF), IDS, and the ESRC-DFID Impact Initiative for International Development Research. The pan-African conference built on a previous IDS-hosted research day involving international non-
The physical events and the online discussion were chaired by Dr Keetie Roelen, IDS Research Fellow and representing IDS within the Coalition.

Keetie is a development economist by training and current research interests include the dynamics of (child) poverty, social protection, and the linkages between child protection and social protection.

Keetie has worked with many international organisations such as UNICEF, the Food and Agriculture Organization of the United Nations (FAO), and Concern Worldwide, performing research and policy advice work in South East Asia, Southern and Eastern Africa, and Central and Eastern Europe. governmental organisation campaigners and academics in November 2016.

Key policy themes emerged from these conferences that may otherwise have been absent from the global movement's work on child poverty and inequality. The subsequent 'What Works for Africa's Poorest Children' conference, facilitated by UNICEF Uganda and the University of Manchester in September 2018, built on the conference's framing and themes, reflecting its broader impact. New relationships and collaborations were also established, including an invitation to an ESRCDFID-funded research team working in Ethiopia to join a ministerial sponsored event on child poverty.

This paper documents key points made by participants at the virtual event in May 2020 at which we reflected on the process from the perspectives of both ESRC-DFID grant holders and members of the Coalition when connecting research with global movements and using research to achieve change.

\section{BENEFITS}

There is power in the 'collective'. Experiences of engaging with wider, global movements indicate that it may be unlikely for one study or piece of research to substantially impact policy agendas. Instead, the combination of smaller studies or the collection of findings from across multiple studies are important to create a critical mass and shift current practice and dominant policy narratives.

Combining research findings can happen in a variety of ways, ranging from meta-reviews to initiatives that provide a space for research on similar topics to be connected (such as the Impact Initiative). Doing so is not self-evident: funding, time, and capacity are crucial to making this happen.

A key to success in the partnership between the Impact Initiative and the Coalition is believed to be the integral role that research organisations play within the Coalition. Research organisations have been part of the Coalition since it was formed, and this has meant that research is embedded throughout rather than seen as a separate consideration. This point was clearly made by panellist David Stewart (CoChair - Global Coalition to End Child Poverty, UNICEF):

\section{What it means is that we're talking with researchers all the time about everything we do; it adjusts what we focus on and what we talk about. The Coalition's individual members are highly influenced, I think, by the research they're hearing about.}

A second key to success is the ability to bring together different groups of people across the research and policy spheres in different configurations over a longer period of time, and to engage face to face. The virtual event built on relationships that have developed in physical spaces. This includes the aforementioned three conferences held between 2016 and 2019, each of them engaging academics, policymakers, and practitioners around a set 
of core themes. Doing so allowed for conversations to build on each other and for messaging to be reinforced and to evolve. The fact that meetings were planned around an overarching policy focus (i.e. reducing child poverty) facilitated this gathering of key people who may not otherwise have convened.

Similarly reflecting on the effectiveness of large-scale events, Nicola Ansell, Brunel University, outlined the benefits of cross-sector collaboration and the ability to engage with stakeholders at national, regional, and global levels. In relation to the 2017 conference, she said:

I'm used to presenting my findings crafted for particular audiences. But I think this was an opportunity for researchers broadly working on child poverty to come together and have a dialogue and effectively to present $a$ wider discourse and to engage in ways of thinking alongside the wider policy community.

'In this time of Covid and in the times [sic] of climate change, it's challenging, but these events that bring people together are incredibly useful. The amount of stuff that happens in these meetings and interactions and the time you give yourself to learn... from others, it's hard to see how that could be done in another way, although in both the short and long term it's likely to be necessary.'

David Stewart, Co-Chair - Global Coalition to End Child Poverty, UNICEF

\section{IMPACT LESSONS}

Highlighted was the need for links between research and policy to be built from the start of a research process and be maintained throughout. However, it was also recognised that this is not always straightforward.

Five main challenges need to be overcome to ensure research relevance and impact:

1. In recognition that research and linking research with policy and other actors is not a linear process, flexibility is key. Funding priorities may shift and external (including political) realities - Covid-19 being a case in point - may change. This necessitates an adaptive approach to linking research with policy and practice.

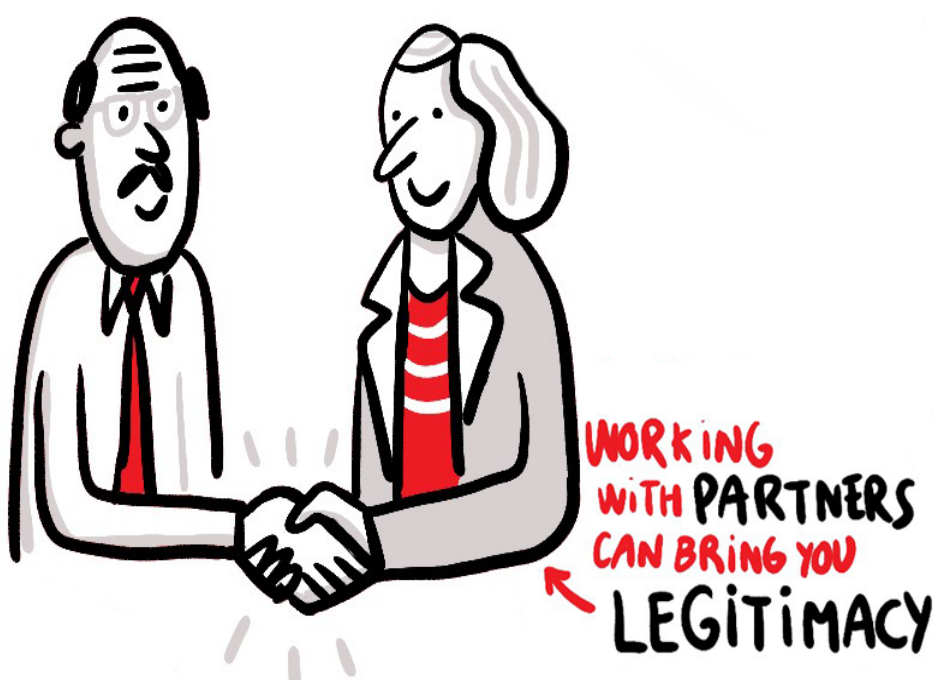

2. Relatedly, time frames for research may not always be aligned with key moments for creating policy impact. Building relationships throughout the research process is vital to lay the foundation for disseminating findings and prompting interest, even if timings do not necessarily align perfectly.

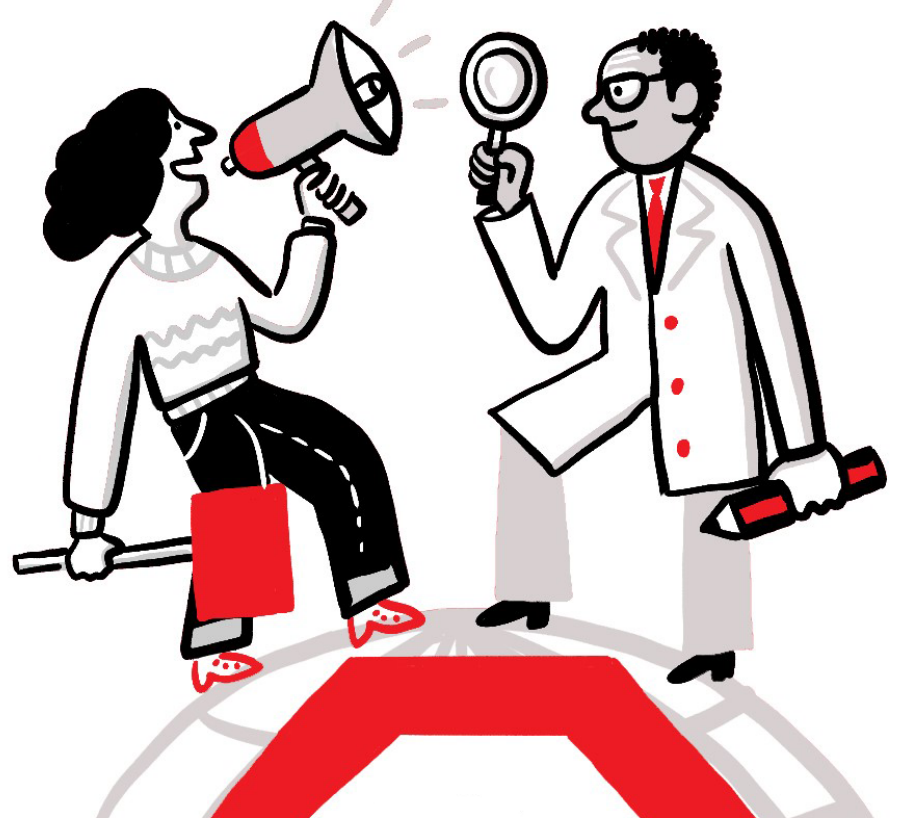

Nicola Ansell, Brunel University, noted:

'You spend an awful lot of time doing the research, designing it, collecting data, analysing that data and then only toward the end of that, do you actually have anything really concrete that you can feel that you can... robustly say... it is very useful to engage with research users throughout to find out what we're talking about so that you can sort of pitch what you're saying to them and think about those areas for possible impact as you go along.'

Similarly, Ricardo Sabates, Cambridge University, reflected on the speed at which researchers are required to provide information but that results can change over time. He pointed out that recommendations targeting different audiences require the researcher to present information in different formats: 'I'm polishing and re-polishing and polishing... as results change, I can blog about them'. 
3. Research needs to be presented in such a way that it is appealing and digestible for policymakers and other stakeholders. Research findings need to be transformed into clear and concise messages that respond to the information needs of a range of actors and can benefit from being communicated using short briefs or other more innovative audiovisual methods.

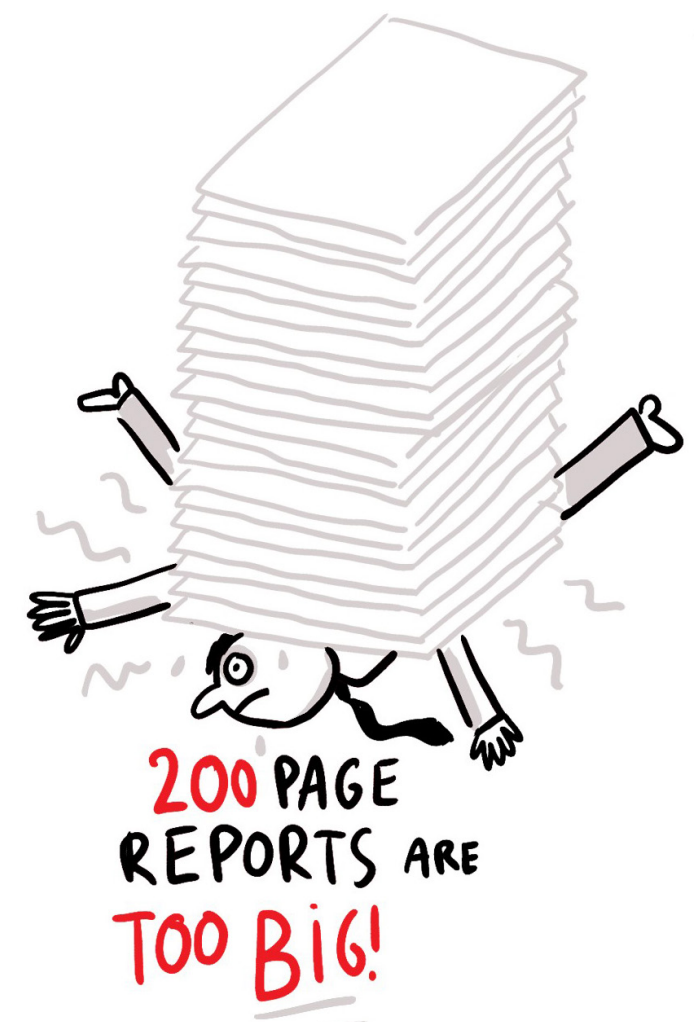

Thokozile Ruzvidzo, Gender, Poverty and Social Policy Division, UNECA, stressed this point:

Sometimes the research institutions make the mistake of making ... [their] research reports very academic, to the point that ... [the research] becomes useless.... Policymakers don't have time to read long reports, so we need to be very strategic. Whilst we know... our own network of researchers in institutions [and] in academia... [will read them], the policymakers will not read those long reports

Whilst packaging content into accessible formats may not be a new idea, experience of working in multi-disciplined groups offers clear recommendations for impactful outputs. These include:

- In acknowledging the need for making research and its findings accessible, messages should not be dumbed down. While many policy actors will not have much time to digest detailed and nuanced findings, they also need to be aware of the complexities and context-specific nature of many issues.

- Appropriate language is crucial. This includes the need to move away from jargon and 'academic speak'. In addition, the use of English as the dominant language needs to be challenged in an attempt to make research more accessible to wider global and sub-national audiences.

- Positive and critical messaging need to be mixed and balanced. If research only highlights negative aspects of policy, its stakeholders are likely to disengage from the research altogether, thereby limiting any potential impact of the research.

'Research findings should be targeted at different levels of policymakers, it should be relevant, and it should be able to give them solutions of what they should be doing. If our research results only raise problems without giving more alternatives of what is possible, we will not get a response'

Thokozile Ruzvidzo, Gender, Poverty and Social Policy Division, UNECA

4. Coalitions should build on the expertise of each partner organisation and be carefully managed to ensure that each remains balanced and on message. In a situation where there may be competing priorities, it is important that a solid partnership model is in place from the beginning. A framework for such partnerships should consider the dynamics of real-world policy engagement whilst balancing the multiple experiences of the participating partners.

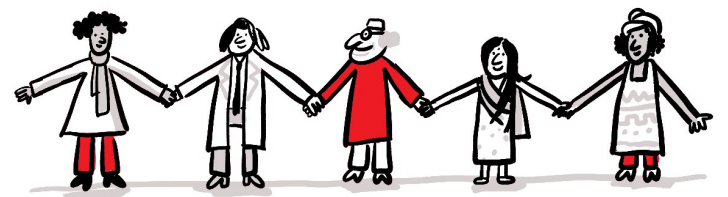

NETWORK BUILDING TO LINK POLICY MAKERS AND RESEARCHERS

5. Relatedly, the spaces that link research with its users need to be more inclusive.

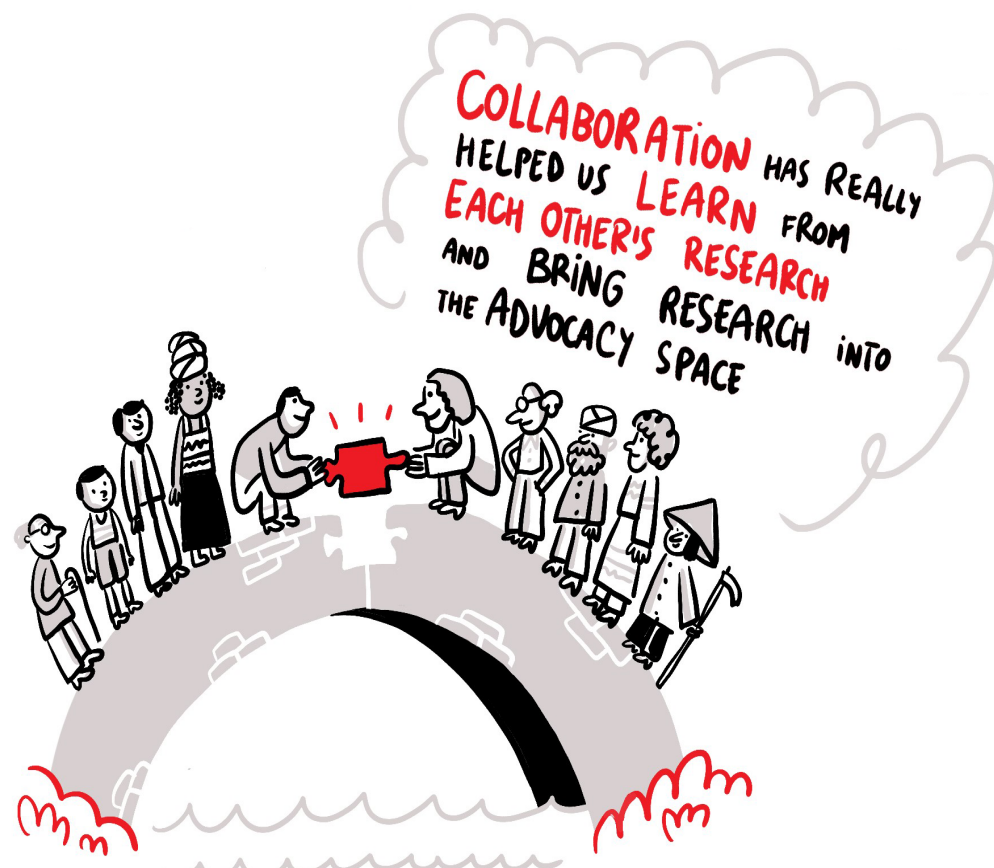


Generally, research undertaken by larger research institutes or prestigious universities is more likely to penetrate the policy sphere and be deemed credible. At the same time, such spaces are more accessible to national-level policymakers or actors within larger international organisations. Actors at the sub-national level or representatives from smaller or grass-roots organisations may be left out of conversations. Making these spaces more inclusive requires engagement with 'unusual suspects' and a commitment to work in more accessible language. Global movements have the ability to engage with a range of actors and bridge the gap.

Overall, the virtual discussion concluded that there is clear benefit to working in more connected ways. International movements can be central to boosting research outcomes by forging new collaborations and developing ideas, skills, and expertise. However, they need to be carefully managed and more inclusive in their approach in order to have the desired impact.

\section{ESRC-DFID RESEARCH EVIDENCE FOR POLICYMAKERS AND PRACTITIONERS}

This virtual gathering built on previous events and outputs by bringing together available evidence on child poverty and its policy responses as well as knowledge and policy gaps.

- The Impact Initiative's downloadable booklet presents research evidence from the ESRC-DFID Strategic Partnership and provides a map and glossary of 38 projects in 22 countries focused on children and young people enabled by the Joint Fund for Poverty Alleviation Research and the Raising Learning Outcomes in Education Systems Programme: ESRC-DFID Research on Children and Youth in Africa.

- A key issue guide highlights ESRCDFID research from the Joint Fund for Poverty Alleviation Research that has directly engaged young people or looked at the factors that enable (or inhibit) their ability to influence what happens in their lives: 'Research with
Children and Young People: How Children's Choices Influence their Wellbeing and How Research can Help'.

- An Evidence Synthesis Research Award (ESRA) report (and summary) explores the specific achievements and contributions of research on children and young people from the ESRC-DFID Joint Fund for Poverty Alleviation Research: 'New Knowledge on Children and Young People: A Synthesis of Evidence.'

- An analysis of partnership dynamics in research-policy collaborations and the literature on development partnerships provide a framework for effective partnership: 'The Power of Partnerships: How to Maximise the Impact for Research for Development'.

- The Coalition and ESRC-DFID grant holders were asked to finish off the statement: 'Research for child poverty has to...?'

\section{Credits}

This Working Paper was written by Keetie Roelen, IDS Research Fellow and representing the Institute of Development Studies (IDS) within the Global Coalition to End Child Poverty, and Kelly Shephard, Head of Knowledge, Impact and Policy, IDS.

Direct quotes included throughout this paper are sourced from the webinar recording and transcription notes - these are included with kind permission from the individuals concerned.

All Images: (c Jorge Martin 2020

The Impact Initiative seeks to connect policymakers and practitioners with world-class social science research supported by the ESRC-DFID Strategic Partnership, maximising the uptake and impact of research from: (i) the Joint Fund for Poverty Alleviation Research, and (ii) the Raising Learning Outcomes in Education Systems Programme.

The Impact Initiative endeavours to identify synergies between these programmes and their grant holders, support them to exploit influencing and engagement opportunities, and facilitate mutual learning. The Impact Initiative is a collaboration between IDS and the University of Cambridge's Research for Equitable Access and Learning (REAL) Centre.

This is a product of the Impact Initiative. The material has been funded by the Economic and Social Research Council and UK aid from the UK Government. However, the views expressed do not necessarily reflect the official policies of the UK Government or ESRC.

\section{$\triangle$ info@theimpactinitiative.net \\ www.theimpactinitiative.net \\ @The_Impact_Init \#ImpactLessons}

All content is available under the Open Government License v.3.0, except where otherwise stated.

(c) Institute of Development Studies, 2020

ISBN 978-1-78118-670-1

DOI: $10.35648 / 20.500 .12413 / 11781 / \mathrm{ii} 350$ 